\title{
Effectiveness of Initial Extracorporeal Shock Wave Therapy on the Newly Diagnosed Lateral or Medial Epicondylitis
}

\author{
Sang Seok Lee, M.D., Sangkuk Kang, M.D., Noh Kyoung Park, M.D., Chan Woo Lee, M.D., \\ Ho Sup Song, M.D. ${ }^{1}$, Min Kyun Sohn, M.D. ${ }^{2}$, Kang Hee Cho, M.D. ${ }^{2}$, Jung Hwan Kim, M.D. ${ }^{3}$ \\ Department of Rehabilitation Medicine, ${ }^{1}$ Orthopedic Surgery, Daejeon Sun Hospital, Daejeon 301-725, \\ ${ }^{2}$ Rehabilitation Medicine, School of Medicine, Chungnam National University, Daejeon 301-721, ${ }^{3}$ Rehabilitation Medicine, \\ School of Medicine, Kangwon National University and Hospital, Chuncheon 200-722, Korea
}

\begin{abstract}
Objective To evaluate the effectiveness of initial extracorporeal shock wave therapy (ESWT) for patients newly diagnosed with lateral or medial epicondylitis, compared to local steroid injection.

Method An analysis was conducted of twenty-two patients who were newly confirmed as lateral or medial epicondylitis through medical history and physical examination. The ESWT group $(n=12)$ was treated once a week for 3 weeks using low energy $\left(0.06-0.12 \mathrm{~mJ} / \mathrm{mm}^{2}, 2,000\right.$ shocks), while the local steroid injection group $(\mathrm{n}=10)$ was treated once with triamcinolone $10 \mathrm{mg}$ mixed with $1 \%$ lidocaine solution. Nirschl score and 100 point score were assessed before and after the treatments of 1st, 2nd, 4th and 8th week. And Roles and Maudsley score was assessed one and eight weeks after the treatments.

Results Both groups showed significant improvement in Nirschl score and 100 point score during the entire period. The local steroid injection group improved more in Nirschl score at the first week and in 100 point score at the first 2 weeks, compared to those of the ESWT group. But the proportion of excellent and good grades of Roles and Maudsley score in the ESWT group increased more than that of local steroid injection group by the final 8th week.

Conclusion The ESWT group improved as much as the local steroid injection group as treatment for medial and lateral epicondylitis. Therefore, ESWT can be a useful treatment option in patients for whom local steroid injection is difficult.
\end{abstract}

Key Words Extracorporeal shock wave therapy (ESWT), Local steroid injection, Lateral epicondylitis, Medial epicondylitis

Received April 26, 2012; Accepted August 1, 2012

Corresponding author: Sangkuk Kang

Department of Rehabilitation Medicine, Daejeon Sun Hospital, 10-7, Mok-dong, Jung-gu, Daejeon 301-725, Korea

Tel: +82-42-220-8468, Fax: +82-303-3130-8468, E-mail: rmactksk@naver. com

(c) This is an open-access article distributed under the terms of the Creative Commons Attribution Non-Commercial License (http:// creativecommons.org/licenses/by-nc/3.0) which permits unrestricted noncommercial use, distribution, and reproduction in any medium, provided the original work is properly cited.

Copyright $\odot 2012$ by Korean Academy of Rehabilitation Medicine

\section{INTRODUCTION}

Lateral or medial epicondylitis of the elbow is a common upper extremity disorder which is characterized by degenerative changes in the musculotendonous region of the epicondyle, resulting from repetitive stress of flexion and extension movements of the wrist joint. ${ }^{1}$ There are various treatment options for the condition including resting, physical therapy, NSAID, steroid injection, ex- 
ercise therapy and orthosis. However, the optimal treatment method remains an open question. Furthermore, surgical managements are occasionally required when conservative management has failed. ${ }^{2,3}$

In recent years, extracorporeal shock wave therapy ${ }^{4}$ has been attempted in addition to prolotherapy ${ }^{5}$, autohemotherapy $^{6}$ and Botulinum toxin injection ${ }^{7}$. Extracorporeal shock wave therapy had been commonly used to treat urolithiasis or choledocholithiasis and the therapy was introduced to treat musculoskeletal conditions such as calcific tendinitis of the shoulder joint, lateral epicondylitis of the elbow joint and plantar fasciitis in Germany in 1990's. In addition, the therapy was also introduced to treat plantar fasciitis and chronic epicondylitis of the elbow joint in the United States in 2000's. ${ }^{8}$ Nevertheless, it is hard to find research about the therapy as an initial treatment option because research on the effects of extracorporeal shock wave therapy for lateral or medial epicondylitis of the elbow has been primarily conducted with patients who failed to respond to conservative management after the acute phase. Therefore, this study aimed to evaluate the effectiveness of initial extracorporeal shock wave therapy (ESWT) for the patients newly diagnosed as lateral or medial epicondylitis by comparing to the steroid local injection.

\section{MATERIALS AND METHODS}

\section{Subjects}

Lateral epicondylitis was diagnosed by tenderness on palpation of lateral epicondyle and the provocation test which causes pain while a resistance on extensor tendon is put by extending the wrist joint. Medial epicondylitis was diagnosed by tenderness on palpation of medial epicondyle and pain on medial area of the elbow joint when generating a resistance by flexion and pronation of wrist joint. Study subjects were recruited among patients who attended the outpatient department of rehabilitation medicine in our hospital between January 2010 and December 2010 and who had one of these two diagnoses. Among these patients, 22 patients who were newly diagnosed in this hospital were included in this study. Patients who were diagnosed or had ever had treatments in other hospitals were excluded. We excluded elderly patients, so the age of the subjects were between 30 years old and 65 years old. Also excluded were those patients who had ever had treatments such as NSAID treatment, physiotherapy, exercise therapy and local injection, had medical histories of pregnancy, hemostatic disorders, malignant diseases, systemic infection or local infection of upper extremities and pacemaker. This study protocol was reviewed and approved by the Institutional Review Board of our medical center, and that informed consent was obtained from all study participants.

\section{Methods}

The subjects were classified into two groups by block randomization; the low energy extracorporeal shock wave therapy group consisting 12 patients (7 of lateral epicondylitis and 5 of medial epicondylitis) and the steroid local injection therapy group consisting 10 patients (6 of lateral epicondylitis and 4 medial epicondylitis). For extracorporeal shock wave therapy group, about 2000 shock waves with $0.06-0.12 \mathrm{~mJ} / \mathrm{mm}^{2}$ of low energy flux density were delivered 3 times in the space of 3 weeks with the interval of a week by using Dolarclast ${ }^{\circledR}$ (Electro Medical Systems, Nyon, Switzerland) after identifying the greatest tenderness point by palpation in supine position. The greatest tenderness point was marked by a pen prior to the therapy for the accurate delivery of shock wave and the number of shock waves was reduced down to 1,000 times in the first week for pain tolerance if pain was severe. The effect of the therapy was evaluated one week from the completion of the third therapy.

For the local steroid injection therapy group, $1 \mathrm{~mL}$ of mixed solution injection made with $10 \mathrm{mg}$ of triamcinolone and $1 \%$ lidocaine was administered once into the tenderness point in lateral epicondyle area via $25 \mathrm{G}$ needle using peppering technique once it reached to the bone. The injection was administered after abducting humerus and flexing the elbow joint at $90^{\circ}$ for lateral epicondylitis patients. The same solution was injected once into the tenderness point in the medial epicondyle area for medial epicondylitis patients using the same method after abducting humerus and extending the elbow joint. Additional steroid injection therapy was not administered and the effect was evaluated after 1 week of the injection therapy.

NSAID, meloxicam $7.5 \mathrm{mg}$, was prescribed for the both groups during the first week of the treatments. Physical therapy and exercise therapy were not prescribed and the patients were advised to avoid inappropriate isometric exercise, stretching or any movements which might cause pain in everyday life. 
Table 1. Nirschl Score

\begin{tabular}{ll}
\hline Phase 1 & Mild pain exercise, resolves within 24 hours \\
Phase 2 & Pain with exercise, exceeds 48 hours \\
Phase 3 & Pain with exercise, does not alter activity \\
Phase 4 & Pain with exercise, alters activity \\
Phase 5 & Pain with heavy activities of daily living \\
Phase 6 & $\begin{array}{r}\text { Pain with light activities of daily living, } \\
\text { intermittent pain at rest }\end{array}$ \\
Phase 7 & Constant pain at rest, disrupts sleep \\
\hline
\end{tabular}

The pain and the function of the elbow joint prior to the treatments and 1 week, 2 weeks, 4 weeks and 8 weeks after the treatments were assessed and recorded using Nirschl score ${ }^{9}$ and 100 point scoring system ${ }^{10}$ in order to evaluate the effects of the treatments. In addition to this, subjective satisfaction levels regarding symptom relief were assessed and recorded using Roles and Maudsley score $^{11}$ at the first week and the 8th week after the treatments. A higher phase in Nirschl score meant more persistent and more severe discomfort during daily life movements (Table 1). The 100 point scoring system, modified by Jung et al. ${ }^{10}$ from the evaluation method used by Wang and Chen, ${ }^{12}$ was composed of 40 points of pain score, 30 points of function score, 20 points of muscle strength and 10 points of ROM of the elbow joint (Table 2 ). Visual analogue scale was utilized to record pain scores. If there was no pain, the score was 0 point and the most severe pain was recorded as 10 points. When muscle strength and range of motion (ROM) were normal, their scores were recorded as 0 point and when muscle strength was zero or ROM was $0^{\circ}$, their scores were recorded as 10 points. Roles and Maudsley score was recorded as excellent, good, acceptable and poor according to subjective satisfaction levels of the patients after the treatments. All recordings and extracorporeal shock wave therapy were done by a rehabilitation medicine resident and local steroid injection was administered by a rehabilitation medicine specialist.

\section{Result analyses}

Two-way repeated measures ANOVA was used to compare treatment effects of extracorporeal shock wave therapy and local steroid injection and to compare treatment effects of each group over time.

Chi-square test was also used to assess changes in the subjective satisfaction levels. SigmaStat Window version
Table 2. 100 Point Score

\begin{tabular}{|ll|}
\hline Pain scores & 40 \\
\hline Pain at rest & 10 \\
\hline Pain on stretching & 10 \\
\hline Pressure pain & 10 \\
\hline Chair test pain & 10 \\
\hline Function scores & 30 \\
\hline Pain at rest & 10 \\
\hline Pain during daily activities & 10 \\
\hline Pain at night & 10 \\
\hline Strength scores & 20 \\
\hline Grip strength & 10 \\
\hline Extension-Flexion strength & 10 \\
\hline Range of elbow motion & 10 \\
\hline
\end{tabular}

3.00 was used for statistical analyses and null hypotheses of no difference were rejected if $p$-values were less than 0.05 .

\section{RESULTS}

The age and physical characteristics of the subjects

There were 6 male patients and 16 female patients in 22 subjects. Their average age was $49.2 \pm 7.9$ years old, their average height was $158.7 \pm 7.0 \mathrm{~cm}$ and their average weight was $59.9 \pm 8.6 \mathrm{~kg}$. The average disease duration was $4.9 \pm 1.3$ weeks and 10 patients were affected on the right side and 9 patients were affected on the left side. There were 9 cases of medial epicondylitis and 13 cases of lateral epicondylitis. The average Nirschl score of 22 subjects was $5.5 \pm 0.7$ points and the average 100 points scoring system was $56.6 \pm 7.6$ points prior to the treatments. Local or systemic side effects from the treatments were not observed among the subjects.

There were no significant differences in sex, age, affected sides, affected areas, disease duration, height and weight between the groups (12 patients in extracorporeal shock wave therapy group and 10 patients in steroid local injection group) prior to the treatments (Table 3 ).

\section{Clinical outcomes}

Nirschl score of extracorporeal shock wave therapy group was $5.6 \pm 0.8$ and that of steroid local injection group was $5.5 \pm 0.7$ prior to the treatment. Nirschl scores of each group in a week on completion of the treatments were $4.8 \pm 0.9$ and $3.8 \pm 0.8$, after 2 weeks were $3.8 \pm 0.7$ and 
Table 3. Characteristics of Patients

\begin{tabular}{lcc}
\hline & ESWT & Injection \\
\hline Number of patients & 12 & 10 \\
Gender (male : female) & $3: 9$ & $3: 7$ \\
\hline Age (year)* & $50.4 \pm 12.8$ & $47.8 \pm 11.9$ \\
Lesion side (right : left) & $5: 7$ & $4: 6$ \\
\hline Lesion site (medial : lateral) & $5: 7$ & $4: 6$ \\
\hline Duration of symptom (week)* & $5.1 \pm 1.2$ & $4.7 \pm 1.4$ \\
Weight $(\mathrm{kg})^{*}$ & $60.6 \pm 10.8$ & $59.0 \pm 14.1$ \\
Height $(\mathrm{cm})^{*}$ & $159.3 \pm 8.8$ & $158.0 \pm 11.7$ \\
\hline
\end{tabular}

ESWT: Extracorporeal shock wave therapy

*Values are mean \pm standard deviation

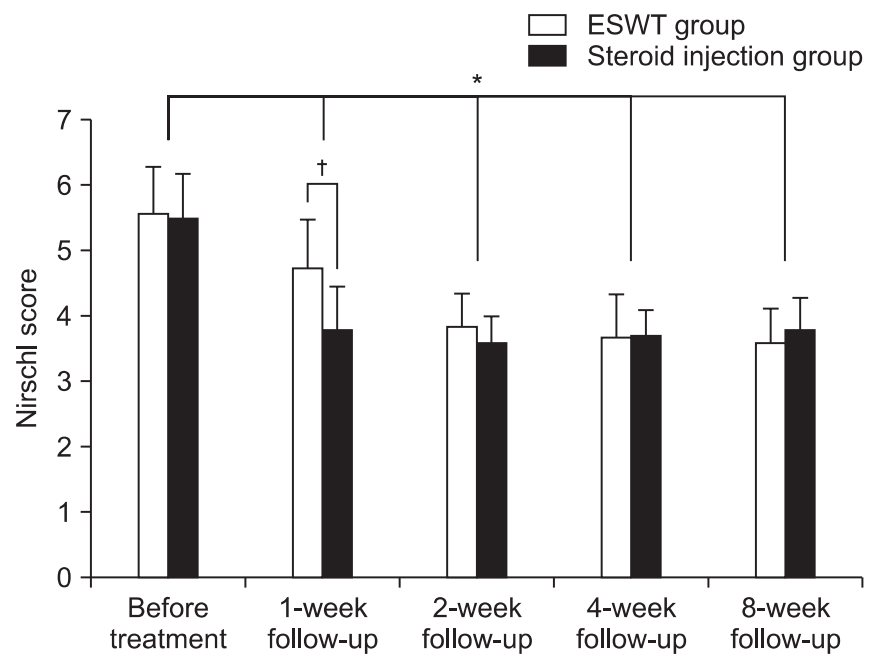

Fig. 1. Nirschl score compared to before treatment and 1-, 2-, 4- and 8-week follow-up. This figure shows significant improvement of both ESWT and local steroid injection group in Nirschlscore during the entire period. Only, local steroid injection group was more effective at the first week. The two way repeated measures ANOVA showed a significant group $\times$ time interaction $\left({ }^{*} \mathrm{p}<0.05\right)$ and a significant effect of two groups at the first week $\left({ }^{\dagger} \mathrm{p}<0.05\right)$. ESWT: Extracorporeal shock wave therapy.

$3.6 \pm 0.5$, after 4 weeks $3.7 \pm 0.8$ and $3.7 \pm 0.5$ and that of each group after 8 week were $3.6 \pm 0.7$ and $3.8 \pm 0.6$ respectively. Improvements from baseline starting one week after treatment to 8 weeks were statistically significant in both groups. Upon completion of treatment, the local steroid injection group had better results after one week but there were no significant differences after that (Fig. 1).

The 100 point scores of extracorporeal shock wave therapy and steroid local injection prior to the treatment were $57.5 \pm 7.9$ and $55.4 \pm 7.4$. The 100 point scores of

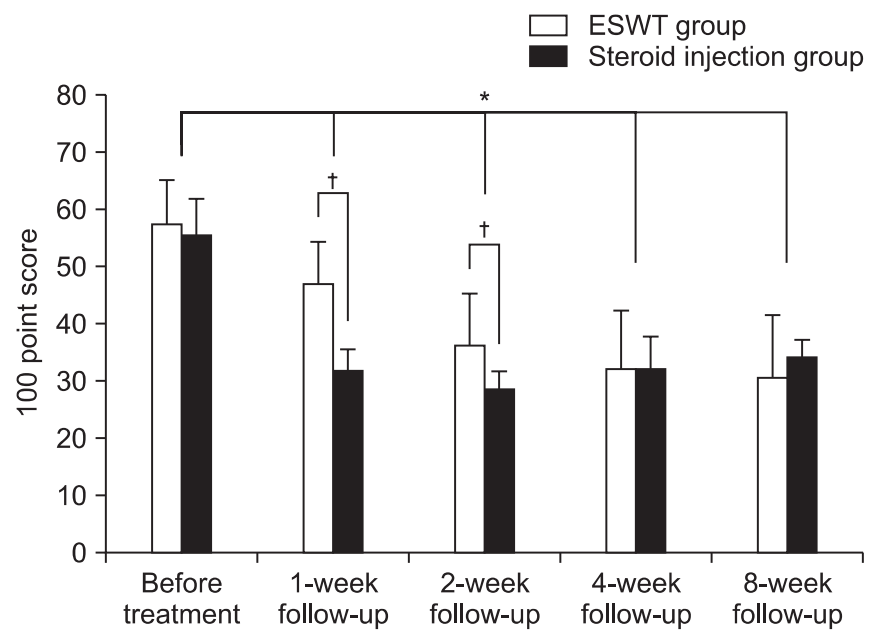

Fig. 2. 100 point score compared to before treatment and 1-, 2-, 4- and 8-week follow-up. This figure shows significant improvement of both ESWT and local steroid injection group in 100 point score during the entire period. The local steroid injection group was more effective at the first 2 weeks. The two way repeated measures ANOVA showed a significant group $\times$ time interaction $\left({ }^{*} \mathrm{p}<0.05\right)$ and a significant effect of two groups at the first 2 weeks $\left({ }^{\dagger} \mathrm{p}<0.05\right)$. ESWT: Extracorporeal shock wave therapy.

Table 4. Roles and Maudsley Score at 1- and 8-week Follow-up

\begin{tabular}{cccc}
\hline & $\begin{array}{c}\text { ESWT } \\
(\mathbf{n}=12)\end{array}$ & $\begin{array}{c}\text { Injection } \\
(\mathbf{n = 1 0})\end{array}$ & p-value \\
\hline 1-week follow up* $^{\text {-wo }}$ & & & 0.043 \\
\hline Excellent-Good & $5(41.7 \%)$ & $7(70.0 \%)$ & \\
\hline Acceptable-Poor & $7(58.3 \%)$ & $3(30.0 \%)$ & \\
\hline 8-week follow up & & & 0.021 \\
\hline Excellent-Good & $8(66.7 \%)$ & $4(40.0 \%)$ & \\
\hline Acceptable-Poor & $4(33.3 \%)$ & $6(60.0 \%)$ & \\
\hline
\end{tabular}

All values are given as the number of patients, with the percentage in parentheses

ESWT: Extracorporeal shock wave therapy

${ }^{*} \mathrm{p}<0.05$ : significant differences between the ESWT and steroid injection groups were estimated using chi-square test at the 1-week after the treatment, ${ }^{\dagger} \mathrm{p}<0.05$ : significant differences between the ESWT and steroid injection groups were estimated using chi-square test at 8-week after the treatment

each group in 1 week on completion of treatments were $47.1 \pm 9.5$ and $31.7 \pm 5.0$, after 2 weeks were $36.5 \pm 9.2$ and $28.7 \pm 3.3$, after 4 weeks $32.2 \pm 10.6$ and $32.0 \pm 5.3$ and after 8 weeks were $30.8 \pm 11.2$ and $34.2 \pm 3.5$ with statistically significant reductions in both groups $(\mathrm{p}<0.05)$. Treatment 
effects of steroid local injection group after one week and after two weeks were superior to those of extracorporeal shock wave therapy group but there were no significant differences between the groups afterwards (Fig. 2).

\section{Subjective satisfaction of the subjects}

Roles and Maudsley score was measured in 1 week and 8 weeks on completion of the treatments. Excellent and good were categorized in one group and acceptable and poor were categorized in the other group to compare. There were greater numbers of acceptable-poor grade in extracorporeal shock wave therapy group and there were greater numbers of excellent-good grade in local steroid injection group in a week on completion of the treatment $(\mathrm{p}<0.05$, Table 4). However, the distribution was reversed in 8 weeks on completion of the treatments showing more excellent-good grade in extracorporeal shock wave therapy group and acceptable-poor grade in steroid local injection group ( $\mathrm{p}<0.05$, Table 4$)$.

\section{DISCUSSION}

Extracorporeal shock wave therapy (ESWT) was first introduced to disintegrate renal stone or common duct stone in 1970's and started being used in treatments of various musculoskeletal pain in 1990's. However, its mechanisms or established treatment guidelines remain highly controversial. ${ }^{13-15}$ In the treatment of epicondylitis of the elbow, it has been explained that there are analgesic effects secondary to overstimulation, ${ }^{16}$ changes in permeability of nerve cell membrane ${ }^{17}$ and neovascular formation in enthesis ${ }^{18}$ but none of these have proven to be clear mechanisms through experiments. ${ }^{19}$

This study used low energy extracorporeal shock wave according to the definition of energy dose established by Speed $^{8}$; energy dose above $0.12 \mathrm{~mJ} / \mathrm{mm}^{2}$ was defined as high energy shock wave and energy dose below $0.12 \mathrm{~mJ} /$ $\mathrm{mm}^{2}$ was defined as low energy shock wave. Rompe et al. ${ }^{17}$ reported that histological responses of tendon were dependent on energy dose, hence, high energy shock wave therapy would be more effective in treating pain. In addition, Oh et al., ${ }^{20}$ who compared effectiveness of the treatment according to actual energy dose, also reported that $0.24 \mathrm{~mJ} / \mathrm{mm}^{2}$ of high energy shock wave was more effective than low energy shock wave while treating lateral epicondylitis. On the other hand, local anesthesia might be required when a high energy shock wave was delivered due to severe pain and a high energy shock wave greater than $0.60 \mathrm{~mJ} / \mathrm{mm}^{2}$ could cause necrosis of a tendon or semi-permanent damage, from an animal experiment. ${ }^{17}$ Furthermore, research claiming the effectiveness of high energy shock waves were conducted with patients who had calcified changes and chronic clinical progress. ${ }^{10,16,19}$ For this reason, clinical symptoms of the patients in this study were of short duration and 0.06$0.12 \mathrm{~mJ} / \mathrm{mm}^{2}$ of low energy shock wave was used. A study conducted by Pettrone and $\mathrm{McCall}^{21}$ which reported satisfactory outcomes from the delivery of 2,000 low energy shock waves three times with the interval of a week to chronic lateral epicondylitis patients, was referred to this study, and shock wave was used 3 times in this study too. Treatment schedule modification or local anesthesia due to severe pain was not required during the treatment and clinical symptoms also improved continuously from the first week to 8th week. This study produced significant improvements in pain with newly diagnosed lateral or medial epicondylitis patients, who experienced clinical symptoms for a short period of time and had never had other conservative management before, while the majority of existing research was conducted with chronic patients using low energy shock wave, which is less painful than a high energy shock wave. Based on this finding, it is judged that initial low energy extracorporeal shock wave therapy can be another option to treat newly diagnosed epicondylitis patients.

Local steroid injection therapy was compared to the effectiveness of extracorporeal shock wave in this study. There is much more research about local steroid injection therapy than extracorporeal shock wave in treating epicondylitis of the elbow and the research report that local steroid injection is more effective than other conservative managements such as iontophoresis or ultrasound heat therapy, Cyriax exercise therapy and so on..$^{22,23}$ However, Smidt et al. ${ }^{14}$ reported that its short-term effects were superior but the mid-term and the long-term effects were poor in the review of 13 studies. Assendelft et al. ${ }^{24}$ also reviewed 11 researches in order to understand the effectiveness and the safety of the therapy and reported that the therapy was not particularly unsafe but significant effects of the therapy lasted only 2-6 weeks on the completion of the therapy. The reason for the poor longterm effects of local steroid injection was thought to be 
that epicondylitis showed tendinosis manifestation on histological examination in the form of myxoid tissue necrosis, angiofibroblastic proliferation or collagen fibrillar degeneration and steroid injection suppressed collagen generation and weakened tendons resulting in necrosis of tendon in some cases. ${ }^{25}$ On the other hand, another study explained that steroid injection relieved the symptoms and patients overdid movements before tendon was completely healed resulting in tendon damage. ${ }^{26}$ Analysis of the treatments in this study also showed local steroid injection was more effective at the beginning but there were no significant differences between the groups and the subjective satisfaction level in 8 week on the completion of the treatment was less than that in 1 week on the completion of the treatment. This result corresponded to previous research results claiming early effects of local steroid injection were satisfactory but long-term effects were poor, ${ }^{14,23,24}$ because it was thought that the patients started to use the wrist joint repetitively once pain was relieved after local steroid injection resulting in tendon damages in epicondyle and myotendinal junction before the affected area was completely healed. However, it should the possibility be considered that the subjective satisfaction level of extracorporeal shock wave therapy was low because its effects became obvious in later phases.

In this study, local steroid injection group showed superior symptom relief and subjective satisfaction levels at the beginning of the treatment but there were no significant differences in clinical improvements between the groups afterwards and the subjective satisfaction level of extracorporeal shock wave was even higher afterwards. Looking into existing research supporting these results, a number of studies reported that the effects of extracorporeal shock wave therapy lasted up to 6 months along with excellent short-term effects. ${ }^{10,20,21}$ The effects of the therapy lasted until 8 weeks in this study. In contrast, Speed et al. ${ }^{27}$ reported that extracorporeal shock wave therapy was not effective while patients with lateral epicondylitis were treated. However, this conclusion was drawn from only one month follow-up period differing from a number of other studies reporting long-term effects. Therefore, it was judged that the effects of extracorporeal shock wave therapy could be reported differently according to followup periods and evaluation methods of clinical improvements.
Considering a research result that there is no relation between calcified lesions around epicondyle of the elbow joint and the success of extracorporeal shock wave therapy $^{10}$ and the view of Stahl and Kaufman ${ }^{28}$ which various physiotherapies is vital at the beginning of the condition to treat epicondylitis, ESWT should be considered as initial treatment of epicondylitis as well as chronic patients with calcified lesions.

This study was limited because there were only 12 patients who received extracorporeal shock wave therapy and the evaluation period was also only 8 weeks which was too short to assess long-term effectiveness. This was because outpatient's follow-up was limited. Further studies on effectiveness of extracorporeal shock wave will be required with patients who are at the high risk of steroid local injection in treating epicondylitis of the elbow in the future.

\section{CONCLUSION}

This study showed that initial extracorporeal shock wave therapy was effective for the patients newly diagnosed as lateral or medial epicondylitis although the effectiveness on completion of the treatments were inferior than local steroid injection. Therefore, extracorporeal shock wave therapy can be another option when local steroid injection is contraindicated.

\section{REFERENCES}

1. Kraushaar BS, Nirschl RP. Tendinosis of the elbow (tennis elbow). Clinical features and findings of histological, immunohistochemical, and electron microscopy studies. J Bone Joint Surg Am 1999; 81: 259-278

2. Boyd HB, Mcleod AC Jr. Tennis elbow. J Bone Joint Surg Am 1973; 55: 1183-1187

3. Friedlander HL, Reid RL, Cape RF. Tennis elbow. Clin Orthop Relat Res 1967; 51: 109-116

4. Furia JP. Safety efficacy of extracorporeal shock wave therapy for chronic lateral epicondylitis. Am J Orthop (Belle Mead NJ) 2005; 34: 13-19

5. Shin JY, Seo KM, Kim DK, Kim BK, Kang SH. The effect of prolotherapy on lateral epicondylitis of elbow. J Korean Acad Rehab Med 2002; 26: 764-768

6. Connel DA, Ali KE, Ahmad M, Lambert S, Corbett S, Curtis M. Ultrasound-guided autologous blood injec- 
tion for tennis elbow. Skeletal Radiol 2006; 35: 371-377

7. Wong SM, Hui AC, Tong PY, Poon DW, Yu E, Wong LK. Treatment of lateral epicondylitis with botulinum toxin: a randomized, double-blind, placebo-controlled trial. Ann Intern Med 2005; 143: 793-797

8. Speed CA. Extracorporeal shock-wave therapy in the management of chronic soft-tissue conditions. J Bone Joint Surg Br 2004; 86: 165-171

9. Nirschl RP. Elbow tendinosis: tennis elbow. Clin Sports Med 1992; 11: 851-870

10. Jung KH, Hwang JH, Chang HJ, Yoon YC, Park MJ, Yoo JC, Park WH. Low-energy extracorporeal shock wave therapy on chronic epicondylitis of the elbow: clinical and sonographic study. J Korean Acad Rehab Med 2009; 33: 77-83

11. Roles NC, Maudsley RH. Radial tunnel syndrome: resistant tennis elbow as nerve entrapment. J Bone Joint Surg Br 1972; 54: 499-508

12. Wang CJ, Chen HS. Shock wave therapy for patients with lateral epicondylitis of the elbow: a one- to twoyear follow-up study. Am J Sports Med 2002; 30: 422425

13. Struijs PA, Smidt N, Arola H, van Dijk CN, Buchbinder $\mathrm{R}$, Assendelft WJ. Orthotic devices for the treatment of tennis elbow. Cochrane Database Syst Rev 2001; 1: CD001821

14. Smidt N, van der Windt DA, Assendelft WJ, Deville WL, Korthals-de Bos IB, Bouter LM. Corticosteroid injections, physiotherapy, or a wait-and-see policy for lateral epicondylitis: a randomised controlled trial. Lancet 2002; 359: 657-662

15. Buchbinder R, Green S, Bell S, Barnsley L, Smidt N, Assendelft WJ. Surgery for lateral elbow pain. Cochrane Database Syst Rev 2002; 3: CD003525

16. Rompe JD, Hope C, Kullmer K, Heine J, Burger R. Analgesic effect of extracorporeal shock-wave therapy on chronic tennis elbow. J Bone Joint Surg Br 1996; 78: 233-237

17. Rompe JD, Kirkpatrick CJ, Kullmer K, Schwitalle M, Krischek O. Dose-related effects of shock waves on rabbit tendon Achillis. A sonographic and histological study. J Bone Joint Surg Br 1998; 80: 546-552

18. Takahashi N, Wada Y, Ohtori S, Saisu T, Moriya H. Application of shock waves to rat skin decreases calcito- nin gene-related peptide immunoreactivity in dorsal root ganglion neurons. Auton Neurosci 2003; 107: 8184

19. Haake M, Konig IR, Decker T, Riedel C, Buch M, Muller HH. Extracorporeal shock wave therapy in the treatment of lateral epicondylitis: a randomized multicenter trial. J Bone Joint Surg Am 2002; 84-A: 19821991

20. Oh JH, Yoon JP, C Oh HH, Jo KH, Gong HS. Doserelated effect of extracorporeal shock wave therapy for lateral epicondylitis. J Korean Shoulder Elbow Soc 2009; 12: 21-26

21. Pettrone FA, McCall BR. Extracorporeal shock wave therapy without local anesthesia for chronic lateral epicondylitis. J Bone Joint Surg Am 2005; 87: 1297 1304

22. Labelle H, Guibert R, Newman N, Fallaha M, Rivard $\mathrm{CH}$. Lack of scientific evidence for the treatment of lateral epicondylitis of the elbow. An attempted metaanalysis. J Bone Joint Surg Br 1992; 74: 646-651

23. Verhaar JA, Wakenkamp GH, van Mameren H, Kester $A D$, van der Linden AJ. Local corticosteroid injection versus Cyriax-type physiotherapy for tennis elbow. J Bone Joint Surg Br 1996; 78: 128-132

24. Assendelft WJ, Hay EM, Adshead R, Bouter LM. Corticosteroid injections for lateral epicondylitis: a systematic overview. Br J Gen Pract 1996; 46: 209-216

25. Kim JM, Kang SY, Hwang JH. The effect of exercise after local steroid injection on the rabbit Achilles tendon. J Korean Acad Rehab Med 2002; 26: 769-775

26. Kim SK, Kim JM, Park HS, Shin HJ, Hwang CH. Spontaneous bilateral Achilles tendon rupture after local steroid injection for carpal tunnel syndrome in a diabetic patient. J Korean Acad Rehab Med 2009; 33: 715717

27. Speed CA, Nichols D, Richards C, Humphreys H, Wies JT, Burnet S, Hazleman BL. Extracorporeal shock wave therapy for lateral epicondylitis-a double blind randomized controlled trial. J Orthop Res 2002; 20: 895898

28. Stahl S, Kaufman T. The efficacy of an injection of steroids for medial epicondylitis. A prospective study of sixty elbows. J Bone Joint Surg Am 1997; 79: 1648-1652 